\title{
Optimism and social support: The providers' perspective
}

\author{
MANJA VOLLMANN ${ }^{1}$, BRITTA RENNER ${ }^{2}$, \& HANNELORE WEBER ${ }^{1}$ \\ ${ }^{1}$ University of Greifswald, Germany and ${ }^{2}$ facobs University Bremen, Germany
}

\begin{abstract}
Abstact
It has been presumed that the beneficial health effects of optimism are mediated by social support provided by the social environment. To further analyze this assumption, in two experiments ( $N \quad 240$ and $N$ 120) social responses toward optimists, pessimists, and realists were examined. Participants listened to tape recorded conversations in which optimistic, pessimistic and realistic targets reported how they were dealing with a stressful situation before completing a questionnaire assessing (a) their evaluation of the target's behavior and personality, (b) their attraction to the target, and (c) their willingness to provide the target with social support. Optimistic and realistic targets were viewed more favorably than pessimistic targets, while the behavior of realists was regarded as being more adequate than that of optimists. However, the more positive evaluation of optimists and realists compared to pessimists was not accompanied by a greater willingness to provide them with social support.
\end{abstract}

Keywords: Optimism, pessimism, realism, social attraction, social support, support provider

\section{Introduction}

Among the personality traits that are seen as psychological resources for health and well-being, optimism has proved to be especially valuable. There is strong evidence that optimism promotes both mental and physical health, particularly when facing stressful situations (for an overview, see Scheier, Carver, \& Bridges, 2001).

Two major pathways from optimism to health are currently discussed, namely adaptive coping and social support (cf., Peterson \& Bossio, 2001; Scheier \& Carver, 1987). With respect to coping, optimists were found to be more likely than pessimists to engage in active ways of coping, such as problem-focused coping and information-seeking, particularly in controllable situations. In uncontrollable situations, optimists were more likely to accept the situation and to disengage from unsolvable tasks. Thus, optimists appear to match their strategies to the situational constraints, which is essential to adaptive coping (e.g., Scheier, Weintraub, \& Carver, 1986; Solberg Nes \& Segerstrom, 2006).

Social support has been proposed as a second mechanism which mediates the relationship between optimism and health. It has been theorized that optimists are more socially attractive than pessimists, and consequently they are more likely to be integrated into supportive social networks, and to receive favorable responses from their social environment (e.g., Scheier \& Carver, 1987). Various studies have shown a positive relationship between optimism and perceived available social support, such as the availability of helpful others (e.g., Brissette, Scheier, \& Carver, 2002; Fontaine \& Seal, 1997; Trunzo \& Pinto, 2003), and received social support, such as the frequency of helpful interactions (Aspinwall \& Taylor, 1992).

Most studies on optimism and social support are based on the perspective of the recipients, while the providers' views have been comparably neglected. The question therefore arises as to whether optimists are in fact provided with more social support than pessimists, or merely perceive their social environment as being more supportive.

Assessing social reactions from a providers' perspective suggests that optimists are indeed provided with more social support than pessimists. Studies based on vignettes showed that targets with a negative outlook and pessimistically biased perceptions were less socially accepted than those with a positive outlook and optimistically biased perceptions (Carver, Kus, \& Scheier, 1994; Helweg-Larsen, Sadeghian, \& Webb, 2002).

In addition, recipients' characteristics which are related to optimism appear to increase the willingness of providers to offer support. Specifically, the

Correspondence: Manja Vollmann, Institute of Psychology, University of Greifswald, Franz Mehring Strasse 47, D 17487 Greifswald, Germany. E mail: vollmann@uni greifswald.de 
expression of positive emotions and moods facilitated rewarding social interactions and positive social responses (e.g., Berry \& Hansen, 1996; Harker \& Keltner, 2001). Consistent with these findings, studies on social responses towards depressed people showed that they are more likely to elicit social rejection than non-depressed people (for a review, see Marcus \& Nardone, 1992). In a similar vein, it was found that poor coping decreased other peoples' willingness to provide social support (Dunkel-Schetter \& Skokan, 1990; Schwarzer \& Weiner, 1991; Weber, 2003). For example, breast cancer patients who displayed distress and appeared to have difficulties with coping elicited less favorable social responses from interaction partners than patients who expressed an optimistic view and more positive coping effort (Silver, Wortman, \& Crofton, 1990).

Given that optimists are typically characterized by positive expectations (Scheier \& Carver, 1987), positive mood (e.g., Weber, Vollmann, \& Renner, 2007), and adequate coping behavior (e.g., Aspinwall \& Taylor, 1992; Scheier et al., 1986), the reported findings suggest that social interaction partners in general react more favorably toward optimists than pessimists. Thus, the higher degree of social support typically reported by optimists presumably represents a veridical reflection of the actual support they are provided with, rather than an optimistically biased perception.

\section{Present research}

The present studies extended previous research on optimism and social support in four aspects. First, previous studies predominantly focused on the relationship between recipients' optimism and providers' social acceptance, willingness for future interaction, or social rejection (e.g., Carver et al., 1994; Helweg-Larsen et al., 2002; Silver et al., 1990). The present studies additionally examined the willingness to offer social support from the providers' perceptive.

Second, we included the concept of realism in addition to optimism and pessimism, assuming that realism constitutes a behavior that may be equally or even more socially desirable and attractive than optimism (Colvin, Block, \& Funder, 1995; Paulhus, 1998). Current research on optimism conceptualizes realism and optimism as related or even overlapping concepts. For example, most researchers assume that optimism needs to be in touch with reality to attain positive effects (e.g., Baumeister, 1989; Schneider, 2001), and empirical findings actually suggest that optimists adapt their behavior to objective features of situations (e.g., Scheier et al., 1986; Solberg Nes \&
Segerstrom, 2006). The question therefore arises as to whether the positive social effects of optimism may be due to elements of realism in optimists' behavior. To disentangle the potential overlapping effects of optimism and realism on social responses, we explicitly included realism as a third concept, drawing on previous studies in which prototypical aspects of realism and optimism were identified (cf., Weber et al., 2007).

The third aspect in which the present studies differed from related research is that we applied a more comprehensive view of optimism, pessimism, and realism by conceptualizing the three concepts as affective-cognitive behavior patterns (including cognitive, affective, motivational, and behavioral components), rather than as pure cognitive dispositions (cf. Peterson, 2000; Weber et al., 2007). More specifically, we assume that the social impact of optimism, realism, and pessimism is not only founded in certain expectations, but relies on a pattern of expressed thoughts and intentions, displayed feelings, and actions that become visible and relevant in social interactions. Findings from studies in which optimistic outlook and positive mood were found to be perceived as co-occurring phenomena support this view (Carver et al., 1994; Helweg-Larsen et al., 2002).

Finally, assuming that social responses are not only influenced by the recipients' behavior and personality but also by the situational context (e.g., Schwarzer \& Weiner, 1991; Weber, 2003), we incorporated the controllability of a given situation as an additional factor. Empirical findings suggest that optimists and pessimists differ in the extent to which they match their behavior to situational constraints. Optimists were found to be more likely than pessimists to adapt their coping behavior to the controllability of the situation at hand (e.g., Scheier et al., 1986). Similarly, we found in previous studies assessing social concepts of optimism, realism, and pessimism from an observer's perspective that pessimists were viewed as non-adaptive to the controllability of situations, and as displaying a rather rigid and dysfunctional behavior pattern. Interestingly, optimists were seen as matching their thoughts and feelings to the controllability of situations, but not their goals and actions, whereas realists were seen as adapting their thoughts, feelings, goals, and actions (Weber et al., 2007).

Taken together, the major aim of the present studies was to examine social responses to targets displaying optimistic, pessimistic, or realistic behavior patterns. Social responses were measured in terms of (a) the evaluation of the target's behavior and personality, (b) the attraction to the target, and (c) the intention to offer social support. On the basis of previous findings, it was hypothesized that 
pessimists would generally elicit more negative social responses than optimists and realists, independent of the controllability of the situation. It was also predicted that optimists and realists would elicit comparable positive social responses in controllable situations. However, it was expected that, in uncontrollable situations, realists would be more likely to elicit positive social responses than optimists because they show a more adaptive behavior.

\section{Study 1}

Method

Participants. The sample consisted of 240 nonpsychology students ( $50 \%$ women) from different disciplines with a mean age of 23 years $(S D=3.06)$. Each participant received 10 Euros as compensation for participation.

Stimulus material. The stimulus material consisted of tape-recorded conversations between two flatmates in which the target person enacted an optimistic, pessimistic, or realistic affective-cognitive behavior pattern in response to two moderately stressful situations that differed in controllability. In each case, the target told the flatmate that she/he had fallen in love with someone. In the controllable situation, the target explained that she/he was rejected because the other person wanted to get to know her/him a little better first, while in the uncontrollable situation the target explained that she/he was rejected because the other person did not share her/his feelings. Results of a previous study confirmed that the two situations were perceived as moderately stressful and as significantly different in controllability (Weber et al., 2007).

The conversation between the target and her/his flatmate was staged as a casual meeting in the kitchen. The flatmate started the conversation by asking the target, "Didn't you recently tell me that you met someone you felt attracted to?" and encouraged the target to talk about her/his thoughts, feelings, goals, and actions by asking questions such as "What do you think about it?" and "What are you going to do now?" In response to these questions, the target enacted an optimistic, pessimistic, or realistic affective-cognitive behavior pattern (excerpts of the conversations for the controllable situation can be found in Appendix).

To operationalize the three behavior patterns, we relied on previous studies which had identified thoughts, feelings, goals, and actions considered as prototypical of optimists, pessimists, and realists in dealing with the two situations ${ }^{1}$ (for details see Weber et al., 2007). Based on these studies, the optimistic behavior pattern in the controllable situation was characterized by a positive construal of the situation, positive outcome expectancies, positive feelings, the intention to pursue the goal of winning the other person's love, and making active efforts to do so. In the uncontrollable situation, the optimistic behavior pattern was represented by positive outcome expectancies, an optimistic explanatory style, mixed feelings, the intention to pursue the goal, and active efforts to do so. The pessimistic behavior pattern was characterized in both the controllable and the uncontrollable situation by a negative construal of the situation, negative outcome expectancies, a pessimistic exploratory style, negative feelings, disengagement from the goal, withdrawal, and focusing on distress. The realistic behavior pattern in the controllable situation was represented by accepting the situation, equanimity, affect control, and an observant behavior, namely pursing the goal without actively pushing it. In the uncontrollable situation, the realistic behavior pattern included accepting the situation, mixed feelings, disengagement from the goal, and affect control.

In order to control a possible influence of the target's sex on the participants' judgments, while the flatmate was female, the conversations were recorded with both a female and a male target. In a pre-study with 43 students ( $79 \%$ women), all of the conversations were rated as plausible and very likely to happen between flatmates.

Procedure. The study had a 3 "behavior pattern" (optimistic vs. realistic vs. pessimistic) $\times 2$ "controllability" (low vs. high) $\times 2$ "sex of target" (female vs. male) between-subjects design that was balanced for the sex of participants. The participants were randomly assigned to one of the 12 conditions and were informed that the purpose of the study was to investigate interpersonal perception on the basis of audio-taped conversations. After completing a questionnaire assessing socio-demographic data, the participants were told that they were to listen to a tape-recorded conversation between two flatmates, one of whom would talk about her/his present situation. They were asked to listen to the conversation and to form an impression of the target. After listening to the audiotape, participants completed a questionnaire assessing (a) their evaluation of the target's behavior and personality, (b) their attraction to the target, and (c) their intention to provide the target with social support. Finally, the participants were thanked, given their compensation, and debriefed. 
Measures

Evaluation of the target's behavior and personality. Four items assessed the perceived adequacy and perceived effectiveness of the target's behavior on a 7-point scale ranging from 1 (not at all) to 7 (very much). For measuring perceived adequacy, participants rated how adequate and how acceptable the behavior was $(r=0.50)$. Perceived effectiveness was assessed by ratings of how effective and how successful the behavior was $(r=0.66)$. The two items for perceived adequacy and for perceived effectiveness were averaged, respectively.

The evaluation of the target's personality was measured by six items adapted from Montoya and Horton (2004), with half of the items referring to achievements (e.g., "The person will be successful in life") and to social recognition (e.g., "The person is well respected"), respectively. Ratings were given on a 7-point scale ranging from 1 (strongly disagree) to 7 (strongly agree) and were combined into an evaluation of personality index $(\alpha=0.86)$.

Interpersonal attraction. Interpersonal attraction was assessed by seven items that were adapted from previous studies (e.g., Coyne, 1976; Helweg-Larsen et al., 2002; Montoya \& Horton, 2004; Winer, Bonner, Blaney, \& Murray, 1981), whereby two items assessed affective attraction (e.g., "How much do you like the person?") and five items assessed behavioral attraction (e.g., "I would like to go to a campus party with the person"). Responses were given on a 7-point scale, ranging from 1 (not at all) to 7 (very much). The seven items were averaged to form a total score of interpersonal attraction $(\alpha=0.91)$.

Intention to provide social support. Intention to provide social support was assessed by five items that were adapted from Schwarzer and Weiner (1991). Participants indicated on a 7-point scale, ranging from 1 (definitely no) to 7 (definitely yes), the extent to which they would be willing to provide social support (e.g., "I would be willing to spend time with the person talking and listening'). Ratings on these items were averaged to yield an index of social support intention $(\alpha=0.91)$.

For a manipulation check, participants rated how optimistic, pessimistic, and realistic they thought the target person was on a 7-point scale ranging from 1 (not at all) to 7 (very much).
Results

Manipulation check. Three between-subjects analyses of variance revealed that optimistic targets $(M=6.19, S D=1.11)$ were rated as more optimistic than both pessimistic $(M=1.25, \quad S D=0.61)$ and realistic targets $(M=3.56, \quad S D=1.81)$, $F(2,237)=299.10, p<0.001, \eta^{2}=0.72$, Bonferroni procedure, $p s<0.001$. Additionally, pessimistic targets $\quad(M=6.48, \quad S D=1.10) \quad$ were rated as more pessimistic than both optimistic $(M=1.73, \quad S D=1.13)$ and realistic targets $(M=3.46, \quad S D=1.74), \quad F(2, \quad 237)=256.01$, $p<0.001, \quad \eta^{2}=0.68, \quad$ Bonferroni procedure, $p s<0.001$. Finally, realistic targets $(M=5.33$, $S D=1.42$ ) were rated as more realistic than both optimistic $(M=3.70, S D=1.65)$ and pessimistic targets $(M=3.79, S D=1.53), F(2,237)=28.30$, $p<0.001, \quad \eta^{2}=0.19$, Bonferroni procedure, $p s<0.001$. The manipulation check verified that participants clearly differentiated optimistic, pessimistic, and realistic targets.

Analyses. A 3 (behavior pattern) $\times 2$ (controllability) $\times 2$ (sex of target) multivariate analysis of variance with perceived adequacy of the target's behavior, perceived effectiveness of the target's behavior, evaluation of the target's personality, interpersonal attraction, and intention to provide social support as dependent variables yielded no overall main or interaction effects for the factor "sex of target." Thus, for further data analysis, 3 (behavior pattern) $\times 2$ (controllability) analyses of variance (ANOVAs) were performed, collapsing over the factor "sex of target." Post hoc comparisons between means were conducted by Bonferroni tests with a $p=0.05$ significance level.

The results of the analyses are summarized in Figure 1, which presents the mean ratings of the dependent measures for the three behavior patterns averaged across the two situations.

Evaluation of the target's behavior and personality. The analysis of the perceived adequacy of the target's behavior revealed a significant main effect of "behavior pattern," $F(2,234)=21.02$, $p<0.001, \eta^{2}=0.15$. The realistic behavior patterns $(M=4.83, S D=1.13)$ were evaluated as significantly more adequate than the optimistic behavior patterns $(M=4.16, S D=1.38), p<0.01$, which in turn were evaluated as significantly more adequate than the pessimistic behavior patterns $(M=3.58, S D=1.13)$, $p<0.01$. No other effects were statistically significant, all $F_{\mathrm{S}}<4$, n.s.

The analysis of the perceived effectiveness of the target's behavior yielded a significant main effect of "behavior pattern," $F(2,234)=52.77$, 


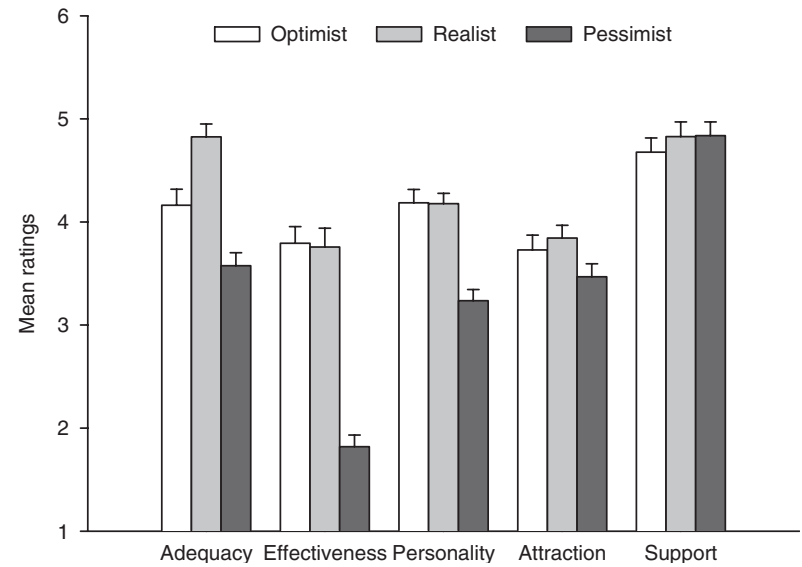

Figure 1. Mean evaluation ratings (with standard errors) of the target as a function of the type of target behavior pattern (Study 1). Note: Higher values indicate a more positive evaluation.

$p<0.001, \eta^{2}=0.31$. Both the realistic and the optimistic behavior patterns $(M=3.76, S D=1.63$ and $M=3.79, S D=1.44$ ) were evaluated as significantly more effective than the pessimistic behavior patterns $(M=1.82, S D=1.01), p s<0.01$. No other effects reached statistical significance, all $F_{\mathrm{S}}<1$, n.s.

Regarding the evaluation of personality, the ANOVA obtained a significant main effect of "behavior pattern," $F(2,234)=23.06, p<0.001$, $\eta^{2}=0.17$. Both realistic and optimistic targets $(M=4.18, S D=0.90$ and $M=4.19, S D=1.16)$ were evaluated significantly more favorably than pessimistic targets $(M=3.24, S D=0.97), p s<0.01$. There were no statistically significant effects on any of the other variables, all $F_{\mathrm{S}}<2$, n.s.

Interpersonal attraction. Contrary to our predictions, no significant main or interaction effects emerged for interpersonal attraction ratings, all $F_{\mathrm{S}}<3$, n.s.

Intention to provide social support. The ANOVA of the social support ratings yielded a significant main effect of "controllability," $F(1$, 234) $=5.38, p<0.05, \eta^{2}=0.02$, with an overall intention to provide social support that was greater in the uncontrollable $(M=4.96, S D=1.24)$ than in the controllable situation $(M=4.60, S D=1.21)$. No other effects were statistically significant, all $F_{\mathrm{S}}<3$, n.s.

\section{Discussion}

Study 1 examined social responses to optimistic, pessimistic, and realistic targets coping with two stressful situations that varied in controllability. The results of this study revealed two main findings. First, with respect to the evaluation of behavior and personality, pessimists were generally perceived in a more negative way than optimists and realists. In particular, pessimistic behavior patterns were seen as less adequate and less effective than optimistic and realistic behavior patterns, and the personality of pessimists was viewed more negatively than that of optimists and realists. These results are consistent with previous findings (Carver et al., 1994; Helweg-Larsen et al., 2002; Silver et al., 1990), and support our assumption that pessimists, with their negative cognitive-affective behavior patterns, are more likely to elicit negative social responses than optimists and realists. However, no significant differences between pessimists, optimists, and realists were found for interpersonal attraction and the intention to provide social support.

Second, while optimists and realists were equally likely to elicit positive social responses, the behavior patterns shown by realists were rated as more adequate than those shown by optimists. With regard to the effectiveness of their behavior, their personality and interpersonal attraction, optimists and realists were evaluated equally positive. Moreover, participants were equally willing to provide optimists with social support as realists. These findings suggest that optimists and realists were perceived as comparably socially attractive. However, contrary to our expectation, these effects were not modulated by the controllability of the situation.

Taken together, the participants' social responses toward the target person appeared to differ as a function of the type of behavior pattern and of the type of social response. Participants appeared to recognize the different behavior patterns since they showed differential cognitive social responses toward the targets, i.e., a more negative evaluation of pessimistic targets. However, these differences were not translated into differential affective social responses, such as a lower attraction to pessimistic targets and a lower willingness to provide them with social support. The finding that pessimists and optimists were perceived as equally socially attractive, and that they elicited a comparable amount of social support, clearly contradicts previous findings showing that pessimists were less socially accepted than optimists (Carver et al., 1994; Helweg-Larsen et al., 2002; Silver et al., 1990).

One possible explanation for these unexpected findings may lie in the situational context in which optimism, pessimism, and realism were presented and evaluated. In the present study, the three behavior patterns were staged in the context of relationship-related stressful situations which may have elicited a general empathy and positive emotional reactions independent of the target's behavior. Conversely, in previous studies, optimism and pessimism were predominately pictured in 
achievement-related or health-related situations. In order to examine the generalizability of the present findings, an additional study was conducted in which two stressful achievement-related situations differing in controllability were realized.

\section{Study 2}

\section{Method}

Participants. Participants were 120 students (50\% women) with a mean age of 24 years $(S D=2.90)$, who received a payment of 5 Euros for their participation.

Stimulus material. As in Study 1, the stimulus material consisted of tape-recorded conversations between two flatmates in which the target person performed an optimistic, pessimistic, or realistic behavior pattern in response to two moderately stressful situations that differed in controllability. In both scenarios, the target had finished her studies and applied for her dream job. In the controllable situation, she was not accepted because she first had to prove her expertise by working there for a day, while in the uncontrollable situation, she was not accepted because there was a hiring freeze due to financial shortages. Results of a previous study confirmed that the two situations were perceived as moderately stressful and as significantly differing in controllability (Vollmann, Renner, \& Weber, 2006).

As in Study 1, the target enacted the optimistic, or pessimistic, or realistic behavior pattern in response to the flatmate's questions (e.g., "Didn't you recently tell me that you have applied for your dream job?"). The behavior of the target was based on prototypical optimistic, pessimistic, and realistic affective-cognitive behavior patterns that had been identified in previous studies ${ }^{1}$ (for details see Vollmann et al., 2006). The basic features of the behavior patterns exhibited by the optimistic, pessimistic, and realistic targets were identical to those shown in the relationship-related situations (see Study 1). Since no effects for the sex of the target were found in Study 1, all conversations were recorded with a female target only. The flatmate was played by a female person.

Procedure and measures. The study had a 3 "behavior pattern" (optimistic vs. realistic vs. pessimistic) $\times 2$ "controllability" (low vs. high) between-subjects design that was balanced for the sex of participants. The participants were randomly assigned to one of the six conditions. The procedure and the measures were identical to those used in Study 1. The reliabilities of the scales were also similar to those found in Study 1: Cronbach's alpha was 0.89 for evaluation of personality, 0.91 for interpersonal attraction, and 0.90 for intention to provide social support.

\section{Results}

\section{Manipulation check}

The three between-subjects analyses of variance revealed that optimistic targets $(M=6.30$, $S D=0.97)$ were rated as more optimistic than both pessimistic $(M=1.23, S D=0.86)$ and realistic targets $(M=5.20, S D=1.45), \quad F(2,117)=225.73$, $p<0.001, \quad \eta^{2}=0.79, \quad$ Bonferroni procedure, ps $<0.001$. Additionally, pessimistic targets $(M=6.40, S D=1.69)$ were rated as more pessimistic than both optimistic $(M=1.50, S D=0.88)$ and realistic targets $(M=2.25, \quad S D=1.34), \quad F(2$, $117)=154.43, p<0.001, \eta^{2}=0.73$, Bonferroni procedure, $p s<0.001$. Finally, realistic targets $(M=6.08, S D=1.16)$ were rated as more realistic than both optimistic $(M=3.90, \quad S D=1.52)$ and pessimistic targets $(M=3.23, S D=1.52)$, $F(2,117)=45.66, p<0.001, \eta^{2}=0.44$, Bonferroni procedure, $p s<0.001$. Accordingly, participants clearly differentiated optimistic, pessimistic, and realistic targets.

\section{Analyses}

The data were analysed by 3 (behavior pattern) $\times 2$ (controllability) analyses of variance (ANOVAs) with Bonferroni post hoc comparisons $(p=0.05)$. The results for the three behavior patterns averaged across the situations are depicted in Figure 2.

Evaluation of the target's behavior and personality. As in Study 1, the analysis of the perceived adequacy of the target's behavior yielded a

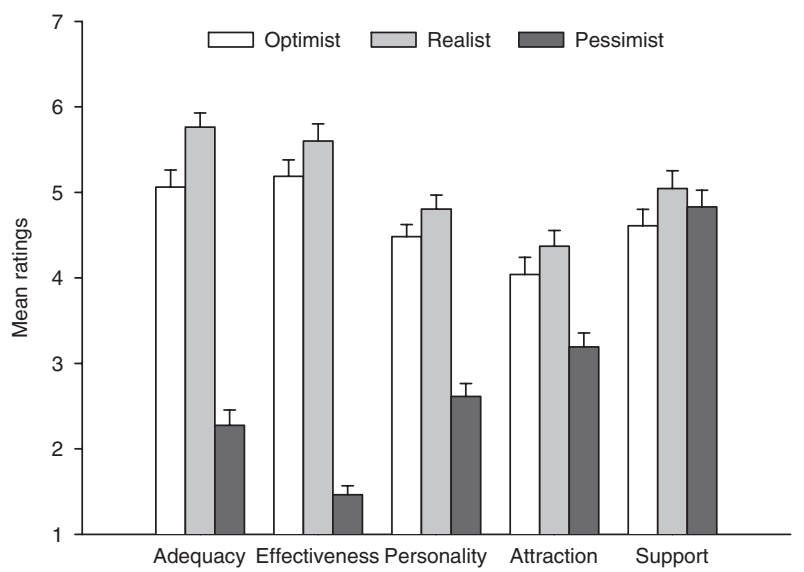

Figure 2. Mean evaluation ratings (with standard errors) of the target as a function of the type of target behavior pattern (Study 2). Note: Higher values indicate a more positive evaluation. 
significant main effect of behavior patterns, $F(2,114)=102.01, p<0.001, \eta^{2}=0.64$. Overall, the realistic behavior patterns $(M=5.76$, $S D=1.06)$ were evaluated as significantly more adequate than the optimistic behavior patterns $(M=5.06, S D=1.26), p<0.05$, which in turn were evaluated as significantly more adequate than the pessimistic behavior patterns $(M=2.28, S D=1.13)$, $p<0.01$. There were no other statistically significant effects, all $F_{\mathrm{s}}<2$, n.s.

As in Study 1, the analysis of the perceived effectiveness of the target's behavior revealed a significant main effect of "behavior pattern," $F(2,114)=171.07, p<0.001, \eta^{2}=0.75$. Both the realistic and the optimistic behavior patterns $(M=5.60, S D=1.28$ and $M=5.19, \quad S D=1.22)$ were evaluated as significantly more effective than the pessimistic behavior patterns $(M=1.46$, $S D=0.66), p s<0.01$. No other effects reached statistical significance, all $F_{\mathrm{s}}<1$, n.s.

As in Study 1, the ANOVA concerning the evaluation of the target's personality yielded a significant main effect of "behavior pattern," $F(2,114)=59.30, \quad p<0.001, \eta^{2}=0.51$. Again, both realistic and optimistic targets $(M=4.80$, $S D=1.04$ and $M=4.48, S D=0.88$ ) were perceived as significantly more favorable than pessimistic targets $(M=2.61, S D=0.95), p s<0.01$. No other effects attained statistical significance, all $F_{\mathrm{S}}<1$, n.s.

Interpersonal attraction. The ANOVA of interpersonal attraction scores yielded a significant main effect of "behavior pattern," $F(2,114)=11.14$, $p<0.001, \eta^{2}=0.16$. Realistic and optimistic targets $(M=4.37, S D=1.15$ and $M=4.04, S D=1.27)$ were rated as significantly more likable than pessimistic targets $(M=3.19, S D=1.03), p s<0.01$. There were no statistically significant effects on any other variable, all $F_{\mathrm{S}}<2$, n.s.

Intention to provide social support. In the analysis of the participants' intention to provide social support, no main effects and interactions attained significance, all $F_{\mathrm{s}}<2$, n.s.

\section{Discussion}

This study examined social responses to optimistic, pessimistic, and realistic targets dealing with achievement-related stressful situations. The results are highly similar to those found for the relationship-related situations examined in Study 1. First, regarding the evaluation of behavior and personality, pessimists were again perceived more negatively than optimists and realists. In contrast to Study 1, pessimists were also perceived as less attractive than optimists and realists, suggesting that a possible general empathy for people in stressful relationship-related situations may not apply in achievement-related contexts. These findings are in line with previous research and provide further evidence for the assumption that pessimists are more likely to elicit social rejection. However, as in Study 1, no differences were found with regard to participants' willingness to provide social support to pessimists, optimists, and realists.

Second, as in Study 1, participants' responses to optimists and realists were highly similar, except that optimistic behavior patterns were again evaluated as less adequate than realistic behavior patterns. However, regarding the perceived effectiveness of behavior, the evaluation of personality, interpersonal attraction, and the intention to provide social support, no significant differences between optimists and realists emerged. Again, these effects were not affected by the controllability of the situation.

\section{General discussion}

The present studies examined social responses toward optimistic, pessimistic, and realistic targets coping with stressful situations varying in controllability and situational context. Extending previous research, the concept of realism was included in addition to optimism and pessimism, and the three concepts were conceptualized as affective-cognitive behavior patterns rather than as pure cognitive concepts. The two studies yielded highly consistent result patterns, suggesting cross-situational consistency in social responses to optimists, pessimists, and realists.

\section{Optimists and pessimists: Do they elicit different social responses?}

In line with previous findings (Carver et al., 1994; Helweg-Larsen et al., 2002; Silver et al., 1990), the present results showed that social responses towards pessimists were generally more negative than towards optimists. In both studies the behavior of pessimists was perceived as less adequate and as less effective than the behavior of optimists. Additionally, participants evaluated the personality of pessimists more negatively and, in Study 2, felt less attracted to them than to optimists. However, although the participants appeared to hold a more negative view of pessimists compared to optimists, they were nonetheless equally willing to provide both with support.

The unequivocally high willingness to provide support to both optimists and pessimists might suggest that optimists are in fact not provided with more social support than pessimists. Accordingly, the 
greater availability of social support commonly reported by optimists (e.g., Brissette et al., 2002) might represent an optimistically biased perception rather than an accurate reflection of the support they are provided with. However, this raises the question how this result could be reconciled with the assumption that social support mediates the relationship between optimism and health? Interestingly, recent empirical evidence suggests that the perceived availability of social support might be more helpful and stress-buffering than actually receiving social support (Helgeson, 2003). Accordingly, one could speculate that optimists and pessimists might predominately differ in perceived available support or in more general terms, how positively they perceive the reactions of others towards them. The present results showed that optimists were evaluated more positively in terms of their behavior and personality than pessimists. Optimists might tend to generalize these positive social responses and therefore perceive more available social support which in turn essentially affects positive health outcomes.

The uniformly high willingness to support both pessimists and optimists might also indicate that the measure was not sensitive enough to detect substantial differences because it focused on initial reactions, and did not distinguish between different types of support. Due to either genuine concern for others or compliance with social norms, persons might be more likely to uniformly demonstrate an initial willingness to support others who are in need. However, such positive initial reactions may change over time, especially when the costs of providing support become increasingly evident. This interpretation is supported by findings showing that the rejection of depressed persons notably increased in long-term interactions when no improvement of mood was observable (Marcus \& Nardone, 1992; Winer et al., 1981). Based on these findings, one could assume that differences in social support provision depending on the recipients' optimism or pessimism may become more pronounced in long-term interactions. Over time, potential support providers might be less willing to provide pessimists with social support than optimists because, due to their persistent negative mood, negative expectations and dysfunctional coping behavior, supporting pessimists might become increasingly resource-demanding.

In addition, people might adapt the type of support they provide to the recipient's seemingly predominant needs. For example, providers may be more inclined to offer pessimists emotional support to improve their negative mood, while being inclined to provide optimists with instrumental support to foster their striving toward goal attainment.
The global measure of social support that was used in the present research may have failed to detect these possible interactions between the type of support and the type of recipient.

Finally, the type of situation may also partly account for the lack of differences in willingness to support. It can be assumed that the presented situations reflect common experiences for students, and that the participants felt highly competent and comfortable in offering support. Hence, these situations might have been less likely to elicit differential effects in support provision than, for example, critical life events that are more likely to induce discomfort and helplessness in providers, due to their lack of experience and competence (Dunkel-Schetter \& Skokan, 1990).

\section{Optimists and realists: Different, but equally liked and supported}

The social responses to optimists and realists were equally positive, except that the behavior patterns shown by realists were generally evaluated as more adequate than those shown by optimists. Thus, participants' perceptions concurred with a normative perspective, according to which goal pursuit in controllable situations and goal disengagement in uncontrollable situations is the most appropriate behavior (e.g., Folkman, 1984; Weber, 2003; Wrosch, Scheier, Carver, \& Schulz, 2003). Although realistic behavior patterns were evaluated as more adequate, they were rated as being equally effective as optimistic behavior patterns. Similarly, optimists were seen as positively as realists in terms of their personality and their attractiveness, and participants were equally willing to provide both with social support. Thus, the participants appeared to recognize the different affective-cognitive behavior patterns shown by optimists and realists, as indicated by the manipulation checks, but this obviously did not lead to differential social responses and support intentions. Accordingly, it can be argued that the positive effects of optimism in previous research were in fact due to an untainted optimistic behavior pattern rather than realistic elements.

Contrary to our expectations, realists did not elicit more favorable social responses than optimists in the uncontrollable situations. One possible explanation for the unvaryingly positive social responses might be that the two uncontrollable situations (unrequited love and a freeze on recruitment) still left some room for positive expectancies, and optimistic goal pursuit may therefore have elicited empathy and understanding, at least in the initial reaction. For future research it would be interesting to examine the degree of (un)controllability at which persistent 
goal pursuit and positive expectations elicit social rejection and refusal of social support.

\section{Limitations}

Several limitations of the present research need to be acknowledged. First, although the two studies yielded highly similar results across the two different life domains, the generalizability of the findings to other domains, for example health-related situations, and to more severe stressors needs to be examined by future studies. Second, the participants' judgments were based on tape-recorded conversations, and this laboratory setting might have restricted the validity of the findings. Compared with actual interpersonal situations, self-reported reactions to scenario-based interactions might be more strongly influenced by social desirability and the desire to comply with social norms. A related limitation is that the present studies assessed the intention or willingness to provide support but not the actual support behavior, which clearly restricts the interpretation of the present results. It would be interesting in future studies to use experimental designs that include real interactions between support providers and recipients and that offer the possibility to observe actual behavior, as was realized in the study of Silver et al. (1990). Finally, the present studies were based exclusively on student samples. Besides sharing this limitation with many other studies, one could certainly argue that other populations, for example older persons or persons with a different cultural background, might hold different views on optimism, realism, and pessimism and they might also have different cultural inclinations towards offering social support and therefore may demonstrate different social reactions.

\section{Conclusions}

Most researchers assume that optimists are provided with more support from their social environment than pessimists, and that this greater social support contributes to their better mental and physical health. However, the present results did not indicate differences in the support providers' intention to offer social support to optimists, realists, and pessimists. Thus, while optimists and realists may well be more liked, and viewed in a more positive way, potential support providers might focus more on the actual needs of their interaction partners, at least in their spontaneous willingness to help. However, differences in support provision that depend on the recipient's behavior and personality might appear in the long run when the cost of providing support becomes increasingly evident. Future research on optimism and social support would profit from study designs and measures that are sensitive to changes over time and possible interactions between type of support and type of recipient.

\section{Acknowledgements}

This research was supported by Grant We 1779/4-1 from the German Research Foundation (DFG) awarded to Hannelore Weber and Britta Renner. The authors would like to thank Katrin Matiba, Kirsten Schweinberger, and Mathias Stamm for their help with data collection.

\section{Note}

1. The prototypical optimistic, pessimistic, and realistic behavior patterns were identified in a multi-level procedure based on a modified version of the act frequency approach (Buss \& Craik, 1983). The behavior patterns consisted of situation-specific thoughts, feelings, goals, and actions that laypersons nominated as prototypical and distinctive coping responses of optimists, pessimists, and realists.

\section{References}

Aspinwall, L. G., \& Taylor, S. E. (1992). Modeling cognitive adaptation: A longitudinal investigation of the impact of individual differences and coping on college adjustment and performance. Fournal of Personality and Social Psychology, 63, 9891003.

Baumeister, R. F. (1989). The optimal margin of illusion. Fournal of Social and Clinical Psychology, 8, 176189.

Berry, D. S., \& Hansen, J. S. (1996). Positive affect, negative affect, and social interaction. Fournal of Personality and Social Psychology, 71, 796809.

Brissette, I., Scheier, M. F., \& Carver, C. S. (2002). The role of optimism in social network development, coping, and psycho logical adjustment during a life transition. Fournal of Personality and Social Psychology, 82, 102111.

Buss, D. M., \& Craik, K. H. (1983). The act frequency approach to personality. Psychological Review, 90, 105126.

Carver, C. S., Kus, L. A., \& Scheier, M. F. (1994). Effects of good versus bad mood and optimistic versus pessimistic outlook on social acceptance versus rejection. Fournal of Social and Clinical Psychology, 13, 138151.

Colvin, C. R., Block, J., \& Funder, D. C. (1995). Overly positive self evaluations and personality: Negative implications for mental health. Fournal of Personality and Social Psychology, 68, 11521162.

Coyne, J. C. (1976). Depression and the response of others. fournal of Abnormal Psychology, 85, 186193.

Dunkel Schetter, C., \& Skokan, L. A. (1990). Determinants of social support provision in personal relationships. fournal of Social and Personal Relationships, 7, 437450. 
Folkman, S. (1984). Personal control and stress and coping processes: A theoretical analysis. Fournal of Personality and Social Psychology, 46, 839852.

Fontaine, K. R., \& Seal, A. (1997). Optimism, social support, and premenstrual dysphoria. Fournal of Clinical Psychology, 53, 243247.

Harker, L., \& Keltner, D. (2001). Expressions of positive emotion in women's college yearbook pictures and their relationship to personality and life outcomes across adulthood. fournal of Personality and Social Psychology, 80, 112124.

Helgeson, V. S. (2003). Social support and quality of life. Quality of Life Research: An International Fournal of Quality of Life Aspects of Treatment, Care and Rehabilitation, 12, 2531.

Helweg Larsen, M., Sadeghian, P., \& Webb, M. S. (2002). The stigma of being pessimistically biased. Fournal of Social and Clinical Psychology, 21, 92107.

Marcus, D. K., \& Nardone, M. E. (1992). Depression and interpersonal rejection. Clinical Psychology Review, 12, 433449.

Montoya, R., \& Horton, R. S. (2004). On the importance of cognitive evaluation as a determinant of interpersonal attraction. Fournal of Personality and Social Psychology, 86, 696712.

Paulhus, D. L. (1998). Interpersonal and intrapsychic adaptiveness of trait self enhancement: A mixed blessing? Fournal of Personality and Social Psychology, 74, 11971208.

Peterson, C. (2000). The future of optimism. American Psychologist, 55, 4455.

Peterson, C., \& Bossio, L. M. (2001). Optimism and physical well being. In E. C. Chang (Ed.), Optimism \& pessimism: Implications for theory, research, and practice (pp. 127 145). Washington, DC: American Psychological Association.

Scheier, M. F., \& Carver, C. S. (1987). Dispositional optimism and physical well being: The influence of generalized outcome expectancies on health. Fournal of Personality, 55, 169210.

Scheier, M. F., Carver, C. S., \& Bridges, M. W. (2001). Optimism, pessimism, and psychological well being. In E. C. Chang (Ed.), Optimism \& pessimism: Implications for theory, research, and practice (pp. 189 216). Washington, DC: American Psychological Association.
Scheier, M. F., Weintraub, J. K., \& Carver, C. S. (1986). Coping with stress: Divergent strategies of optimists and pessimists. Fournal of Personality and Social Psychology, 51, 12571264

Schneider, S. L. (2001). In search of realistic optimism: Meaning, knowledge, and warm fuzziness. American Psychologist, 56, 250263.

Schwarzer, R., \& Weiner, B. (1991). Stigma controllability and coping as predictors of emotions and social support. Fournal of Social and Personal Relationships, 8, 133140

Silver, R. C., Wortman, C. B., \& Crofton, C. (1990). The role of coping in support provision: The self presentational dilemma of victims of life crises. In B. R. Sarason, I. G. Sarason \& G. R. Pierce (Eds.), Social support: An interactional view. Wiley series on personality processes (pp. 397 426). Oxford: John Wiley $\&$ Sons.

Solberg Nes, L., \& Segerstrom, S. (2006). Dispositional optimism and coping: A meta analytic review. Fournal of Personality and Social Psychology, 10, 235251.

Trunzo, J. J., \& Pinto, B. M. (2003). Social support as a mediator of optimism and distress in breast cancer survivors. Fournal of Consulting and Clinical Psychology, 71, 805811.

Vollmann, M., Renner, B., \& Weber, H. (2006). Optimism, pessimism, and realism in achievement related situations. Manuscript in preparation.

Weber, H. (2003). Breaking the rules: Personal and social responses to coping norm violations. Anxiety, Stress and Coping: An International fournal, 16, 133153.

Weber, H., Vollmann, M., \& Renner, B. (2007). The spirited, the observant, and the disheartened: Social concepts of optimism, realism, and pessimism. Fournal of Personality, 75, 169197.

Winer, D. L., Bonner, T. O., Blaney, P. H., \& Murray, E. J. (1981). Depression and social attraction. Motivation and Emotion, 5, 153166.

Wrosch, C., Scheier, M. F., Carver, C. S., \& Schulz, R. (2003). The importance of goal disengagement in adaptive self regulation: When giving up is beneficial. Self and Identity, 2, 120 . 


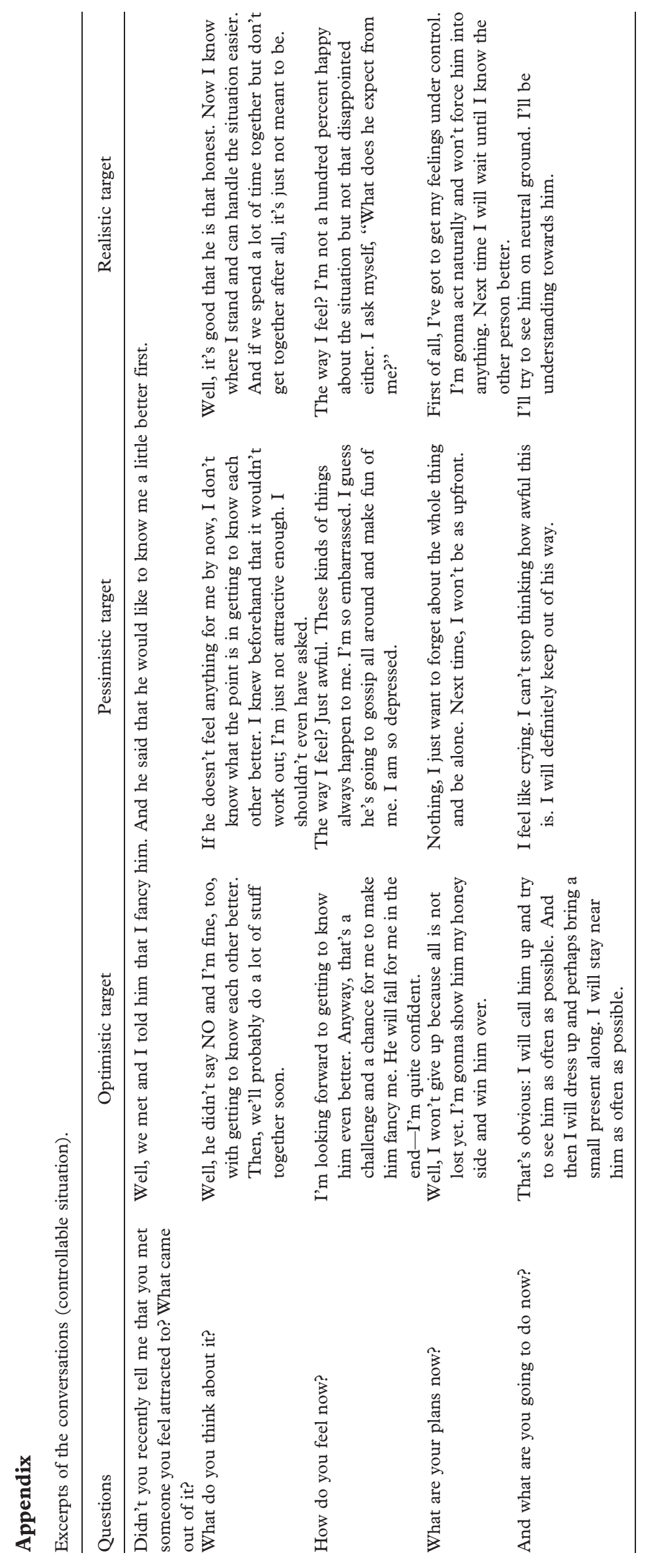

